\title{
Management of Diabetic Foot Ulcer in a Tertiary Level Hospital-Faridpur
}

\author{
Gaddafi $\mathrm{AL}^{1}$, Das $\mathrm{DK}^{2}$, G Faruque ${ }^{3}, \mathrm{Z}$ Islam ${ }^{4}$, Rahman $\mathrm{MA}^{5}$, FN Jui ${ }^{6}, \mathrm{KM} \mathrm{Walid}^{7}, \mathrm{~A} \mathrm{Biswas}^{8}$
}

\begin{abstract}
:
A descriptive type of cross sectional study among 210 diabetic patients with foot ulcer was carried out in Diabetic Association Medical College during the period of May 2016 to April 2017 and were categorized based on Meggitt-Wagner system to find out the complications, management, below knee amputation rate and mortality rate. The aim of this study was to practise a profile of diabetic foot ulcer (DFU), complications and its management to assess the outcome of the surgical interventions. Majority of the patients were male $112(53 \%)$, and most of them 116 patients $(55.23 \%)$ presented within Wegner grade - 2 and grade-3 diabetic foot ulcers. The duration of diabetes more than 10 years was $116(55 \%)$. $99(47 \%)$ patients out of 210 patients developed diabetic neuropathy. 76 (36\%) patients presented with CKD. Lack of awareness about diabetes mellitus and its lower limb complications, poor compliance to the treatment, poorly controlled blood
\end{abstract}

sugar levels, delay in diagnosis, and late presentation to the tertiary care center, associated habit of smoking are all factors which lead to incidence of DFU at an earlier age than that seen in other studies. After admission of diabetic foot ulcer patients, diabetic foot ulcer is classified according to Wagner grading and treated the diabetic foot ulcer patients as the using protocol '!1.Assesment whether it was conservative or surgical. 2. Optimal blood sugar control. 3. Systemic antibiotic. 4. Moist wound environment. 5. Offloading such as total contact casting. 6. Improves peripheral arterial circulation due to lack of vascularity. 7. Surgical debridement or minor amputation or major amputation.

In case of G-4 or G-5 patients, ischemia was treated before debridement or amputation so that vascular circulation improved in the ulcer area and then healing potential was fastened.

Keywords: Diabetic foot ulcer, Management, Meggitt-Wagner grading, Diabetes mellitus.

(Bangladesh Heart Journal 2019; 34(1): 52-57)

Introduction:

The world is facing a major epidemic of diabetes. About 194 million people worldwide or $5.1 \%$ in the age group of 20 to 79 were estimated to have diabetes in 2003 and this estimate is expected to increase to some 330 million or $6.3 \%$ of the adult population by $2025^{1}$. Diabetes mellitus appears to be a global epidemic and increasingly a major non-communicable disease threatening both affluent and non- affluent society ${ }^{2,3}$. More than 170 million people

1. Assistant Professor of Orthopedics, Diabetic Association Medical College, Faridpur. Bangladesh.

2. Associate Professor of Orthopedics, Diabetic Association Medical College, Faridpur. Bangladesh

3. Associate Professor of Orthopedics, Jessore Medical College, Jessore, Bangladesh

4. Assistant Professor of Orthopedics, Jessore Medical College, Jessore, Bangladesh

5. Resident, Department of Physical Medicine and Rehabilitation, BSMMU, Dhaka, Bangladesh.

6. Resident Surgeon, Department of Gynaecology and Obstetrics, Diabetic Association Medical College, Faridpur, Bangladesh

7. Assistant Professor of Endocrinology, Diabetic Association Medical College, Faridpur. Bangladesh.

8. Associate Professor of Respiratory Medicine, Diabetic Association Medical College, Faridpur, Bangladesh.

Address of Correspondence: Dr. Abdullah Al Gaddafi, Assistant Professor of Orthopedics, Diabetic Association Medical College, Faridpur. Cell: +880 1747819408, E-mail: drranajsrbd1983@gmail.com

DOI: https://doi.org/10.3329/bhj.v34i1.41908

Copyright $\odot 2017$ Bangladesh Cardiac Society. Published by Bangladesh Cardiac Society. This is an Open Access articles published under the Creative Commons Attribution-NonCommercial 4.0 International License (CC BY-NC). This license permits use, distribution and reproduction in any medium, provided the original work is properly cited and is not used for commercial purposes. 
worldwide have diabetes and this figure is projected to be more than double by the year 2030, if the current trend is allowed to continue further ${ }^{4}$. One of the major complications of DM is diabetic foot.

The World Health Organization defines, "Diabetic foot as the lower limb of a diabetic patient that has the potential risk of pathological consequences, including infection, ulceration and/or destruction of deep tissues associated with neurologic abnormalities, various degrees of peripheral vascular disease, and/or metabolic complications of diabetes".

Diabetic foot ulcer is the most common cause for prolonged hospitalization. It occurs in $15 \%$ of patients with diabetes in their lifetime $5,6,7$. Risk factors for foot ulcer include male gender, duration of diabetes more than 10 years, peripheral neuropathy, foot deformity, peripheral vascular disease, smoking, history of prior ulcers or amputation, poor glycemic control ${ }^{7,8,9}$, genetic and nutritional factors ${ }^{10}$, diabetic retinopathy and nephropathy ${ }^{11}$.

Among them the main factor is peripheral neuropathy. Diabetic neuropathy can cause insensitivity or a loss of ability to feel pain, heat and cold ${ }^{12}$. Diabetics suffering from neuropathy can develop minor cuts, scrapes, blisters or pressure sores that they may not be aware of due to the insensitivity. If these minor injuries are left untreated, complications may result and lead to ulceration and possibly amputation of toe and even loss of foot ${ }^{13}$. Diabetic peripheral neuropathy can also cause foot deformities such as bunions, hammer toes and charcot's foot. These are resulting from undue bony prominences with high pressure points, leading to callosities and ulcerations ${ }^{10}$

The best approach in dealing with diabetic foot is prevention of ulcer through the identification of individuals at risk, patient education and follow up ${ }^{4}$.

In this study, all cases were known case of type 2 diabetes and neuropathy was the main factor for developing diabetic foot ulcer. This study shows that increasing age, long duration of diabetes, high level of $\mathrm{HbA}_{1} \mathrm{C}$ usually more than $10 \%$, late presentation, inadequate control of diabetes, smoking and lack of education about diabetes increased the risk of diabetic foot.

\section{Materials and methods:}

In this descriptive type of cross sectional study conducted on all diabetic foot ulcer patients in DAMCH, Faridpur from May 2016 to April 2017 were studied.

Inclusion criteria: All type-2 diabetic patients were included in this study.

Exclusion criteria:Diabetic foot patients with septic shock, diabetic ketoacidosis, hyperglycemic hyperosmolar state and electrolyte imbalance were excluded in this study.

Ankle-brachial pressure index, doppler study and retinopathy were excluded in all patients. Detailed history such as age, sex, marital status, smoking, socioeconomic condition, duration of ulcer with associated other condition and standard clinical examination for neuropathy such as callus formation in the foot, claw toes, flat foot, hammer toes, charcot foot, vascular assessment were done. Possible included laboratory investigations such as $\mathrm{Hb} \%$, fasting blood sugar, 2 hours after breakfast, serum creatinine, $\mathrm{HbA}_{1} \mathrm{C}$, ECG were done. Foot ulcers were treated according to Wagner classification.

\section{Wagner grading is given bellow:}

Grade - 0 - No ulceration in a high risk foot.

Grade - 1 - Superficial ulceration

Grade - 2 - Deep ulceration but no bony involvement, no abscess

Grade - 3 - Osteomyelitis or deep abscess

Grade - 4 - Localized gangrene

Grade - 5 - Extensive gangrene

Questions regarding symptoms of neuropathy and vascular disorder including numbness, abnormal hot and cold sensation, tingling sensation, burning pain, aching pain, intermittent claudication, skin discoloration of foot were asked and recorded.

Neuropathy was assessed by tuning fork and monofilament. Areas of callus, necrotic and ulcer area were avoided in testing. Sensory testing was performed at seven locations on each foot using the SemmesWeinstein monofilament. The patient was explained what were we going to be done and why? Then monofilament was applied somewhere on the person, such as the forearm, so that the sensation of the monofilament can be experienced. The person was asked to close his or her eyes and to say "yes" every time the monofilament is felt. The monofilament was applied to the tips of the first, third, and fifth toes on the weightbearing surface of each foot in any order. The person's ability to detect the light pressure of the monofilament was recorded. Any sites that do not invoke a response was rechecked.

The monofilament must be placed at 90 degree to the skin surface. It should be applied and released in a controlled manner, over a period of 1-2 seconds. When applied and held, the monofilament should buckle at about $1 \mathrm{~cm}$ from the horizontal line. It must not "wiggle" or slide when held in place. Inability to detect one or more sites in each foot indicates sensory deficit and increased ulcer risk. 
Sensory testing was also assessed by tuning fork. The tunning fork was held by gripping the flat-ridged area at the base of the thumb and forefinger. With thumb and forefinger the limbs of the tuning fork were pressed together at its tip. Then thumb and forefinger were sharply pulled away allowing the limbs resonate.

The tuning fork was placed on a bony area away from the foot, such as the elbow, so that individual can identify the sensation of the vibrating tuning fork. This process was repeated and the tuning fork was placed on the tip of the individual's great toe and the patient was asked what he or she could feel. There was little need to test anywhere else, for the same reason outlined for 10-g monofilament use.

Peripheral vascular disease was assessed only by palpatory method because hand held doppler was not available in this institute to determine ankle brachial index.

\section{Result:}

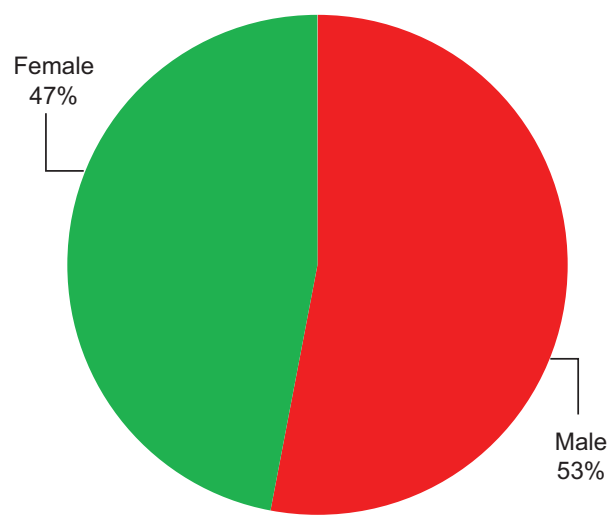

Fig.-1: Distribution of the diabetic foot ulcer patients according to sex.

Fig:1 shows that among 210 DFU patients, 112 (53\%) patients were male and $98(47 \%)$ patients female.

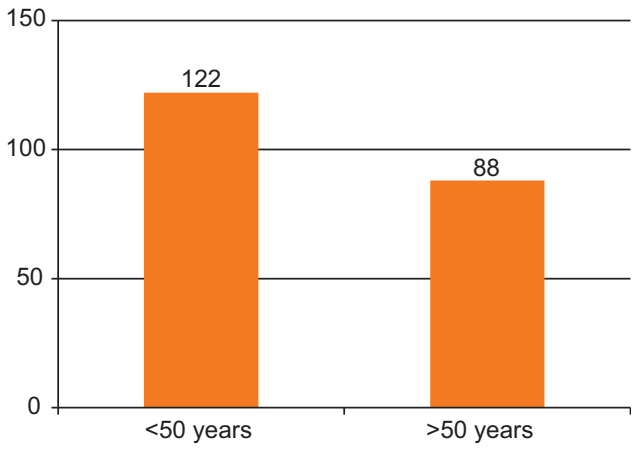

Fig.-2: Distribution of the diabetic foot ulcer patients according to age.
Fig 2 shows that the age of the patients ranged from $40-$ 70 years, where $122(58 \%)$ patients were below 50 years and $88(42 \%)$ patients were above 50 years)

Table-I

Time of attending the health care centre following ulceration.

\begin{tabular}{lcc}
\hline $\begin{array}{l}\text { Onset of diabetic } \\
\text { foot ulcer }\end{array}$ & $\begin{array}{c}\text { Number of } \\
\text { patients }\end{array}$ & Per cent age \\
\hline$<10$ days & 96 & $45 \%$ \\
$10-20$ days & 66 & $31 \%$ \\
$>20$ days & 48 & $24 \%$ \\
\hline
\end{tabular}

Table-1 shows that 96 ( $45 \%$ ) patients attended in this hospital within 10 days, 66 (31\%) patients within 10-20 days and $48(24 \%)$ patients more than of 20 days of onset of symptoms.

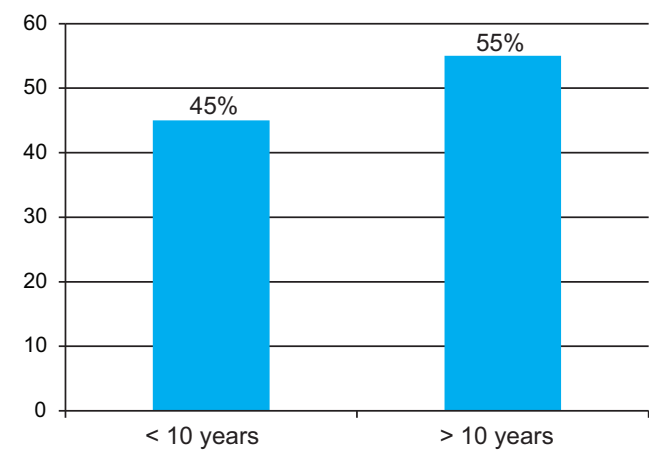

Fig-3: Distribution of the diabetic foot ulcer patient according to duration of diabetes

Fig-3 shows that the duration of diabetes below 10 years was 94 (45\%) patients, where as above 10 years was $116(55 \%)$ patients.

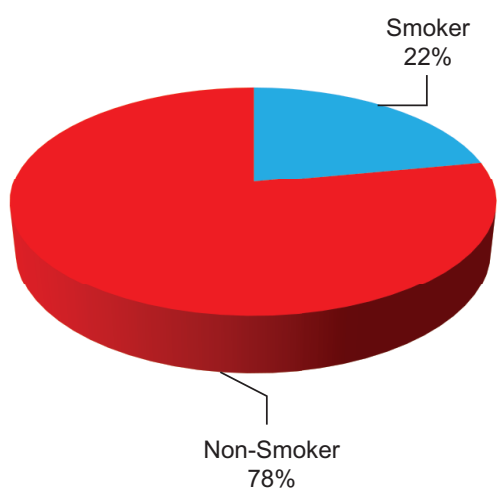

Fig.-4: Distribution of the patients according to smoking habit. 
Fig-4 shows that $47(22 \%)$ patients were smokers and 163 (78\%) patients were non-smokers.

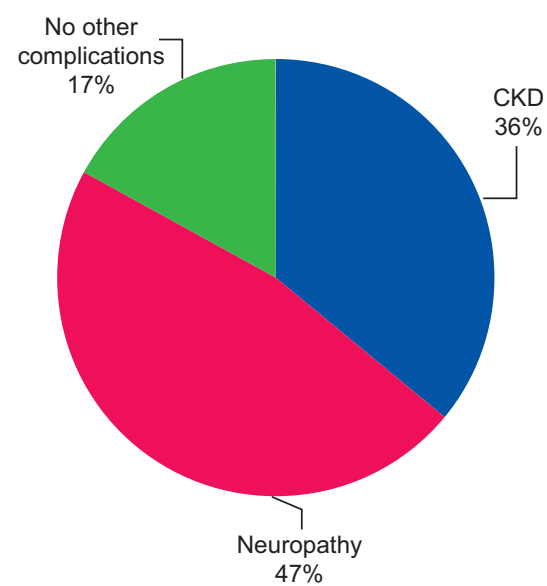

Fig.-5: Diabetic foot ulcer associated with other complications.

Fig-5 shows that 99 (47\%) diabetic foot ulcer patients presented with diabetic neuropathy.76 ( $36 \%$ ) patients presented diabetic foot ulcer as well as chronic kidney disease.35(17\%) patients presented no other complications other than neuropathy and chronic kidney disease.

Table-II

Distribution of patients according to grading of diabetic foot

\begin{tabular}{lcc}
\hline Grade & Number & Percentage \\
\hline$G-1$ & 54 & $26 \%$ \\
$G-2$ & 58 & $28 \%$ \\
$G-3$ & 58 & $28 \%$ \\
$G-4$ & 18 & $8 \%$ \\
$G-5$ & 22 & $10 \%$ \\
\hline
\end{tabular}

Table-2 shows out of the 210 cases, 54 (26\%) patients were in G-1, 58 (28\%) patients were in G-2, 58 (28\%) patients were in G-3, 18 (8\%) patients were in G-4, 22 $(10 \%)$ patients were in G-5.
Table-III

Distribution of the patients according to hemoglobin \& $\mathrm{HbA}^{1} \mathrm{C}$ level

\begin{tabular}{lcc}
\hline $\mathrm{Hb} \%$ & Number & percentage \\
\hline$>10 \mathrm{~g} / \mathrm{dl}$ & 130 & $62 \%$ \\
$<10 \mathrm{~g} / \mathrm{dl}$ & 80 & $38 \%$ \\
$\mathrm{Hb} \mathrm{A}_{1} \mathrm{C}$ & & \\
$7.8-10$ & 103 & $49 \%$ \\
$>10$ & 107 & $51 \%$ \\
\hline
\end{tabular}

Table-3 shows 130 (62\%) patients had Hb level > 10 g/dl and $80(38 \%)$ patients had $<10 \mathrm{~g} / \mathrm{dl}$. $\mathrm{HbA}_{1} \mathrm{C}$ level was $7.8-10 \%$ in 103 (49\%) patients where it was $>10 \%$ in 107 (51\%) patients.

Table-IV

Distribution of patients according to hospital stay

\begin{tabular}{lcc}
\hline Hospital stay (days) & Number & Percentage \\
\hline$<10$ & 97 & $46 \%$ \\
$10-20$ & 65 & $31 \%$ \\
$>20$ & 48 & $23 \%$ \\
\hline
\end{tabular}

Table-4 shows that 97 (46\%) patients had to stay in this hospital below 10 days, 65 (31\%) patients ranged from 10-20 days, 48 (23\%) patients above 20 days. Amputation rates were high in G-4, 5 compared to other Grades.

$54(26 \%)$ patients of G-1 were treated by conservative (1.Optimal blood sugar control. 2. Systemic antibiotic. 3. Moist wound environment. 4. Offloading 5. Improves peripheral arterial circulation due to lack of vascularity) and discharged without any complication where as other Grade patients were treated by operation. 75(36\%) patients of G-2 \& G-3 ulcers were treated by surgical debridement followed by secondary closure or split thickness skin graft. 59(28\%) patients of G-3and G-4 were treated by minor amputation because it could not be preserved due to vascular insufficiency. 22(10\%) patients of G-5 were treated by major amputation .

Table-V

Distribution of patients according to treatment protocols.

\begin{tabular}{|c|c|c|c|c|}
\hline Treatment & $\begin{array}{c}\text { Number and } \\
\text { percentage of G-1 }\end{array}$ & $\begin{array}{c}\text { Number and percentage of } \\
\text { G-2 and G-3 combined }\end{array}$ & $\begin{array}{c}\text { Number and percentage } \\
\text { of G-3 and G-4 }\end{array}$ & $\begin{array}{c}\text { Number and } \\
\text { percentage of G-5 }\end{array}$ \\
\hline Conservative & $54(26 \%)$ & - & - & - \\
\hline $\begin{array}{l}\text { Debridement followed by } \\
\text { secondary closureor split } \\
\text { thickness skin graft. }\end{array}$ & - & $75(36 \%)$ & - & - \\
\hline Minor amputation & - & - & $\begin{array}{cc}\text { G-3 } & 41(19 \%) \\
\text { G-4 } & 18(9 \%)\end{array}$ & \\
\hline Major amputation & - & - & - & $22(10 \%)$ \\
\hline Total Patients (G1-G5) & & & 210 & \\
\hline
\end{tabular}




\section{Discussion:}

In this study, majority of the patients (55\%) had duration of diabetes of more than 10 years and mean duration of symptoms was $9.2 \pm$ SD years. In our study, mean duration of diabetes was dissimilar than those of muduli et al study and Bansal et al study respectively. Slight male predominance was observed as the male female ratio was 1.14 only. On the other hand, the average age of the present study population was similar with that of 54.57 years in muduli et al study and 57.05 years in Bensal et al study respectively. Majority of the patients were non-compliant to the treatment protocol due to prolonged hospital stay, higher cost, delay in healing potential, neglected by their near and dear ones. $51 \%$ patients presented $\mathrm{HbA}_{1} \mathrm{C}>10 \%$ in this hospital which was similar to the other studies ${ }^{14,15}$. In our study, Neuropathy was more prevalent to develop DFU.

Major amputation rate was high in grade 5 and minor amputation was high in greade-4 compared to grade- 3 . G-1 patients $(26 \%)$ were treated conservatively where as other grade (G-2 \& G-3) patients were treated by operation such as surgical debridement followed by secondary closure or split thickness skin graft or minor amputation . $97(46 \%)$ patients had to stay in this hospital below 10 days, $65(31 \%)$ ranged from $10-20$ days, $48(23 \%)$ above 20 days . 96 ( $45 \%$ ) patients were attended in this hospital within 10 days of onset of developing ulcer, 66 (31\%) patients within $10-20$ days and $48(24 \%)$ patients more than 20 days of onset of developing ulcer which were late presentation due to insensitive foot, unawareness of lower limb complication .

In this study, DFU was a complication seen exclusively in diabetic patients and it developed usually in the sixth and the seventh decades of life which was compatible with other studies ${ }^{14,15}$. It usually developed at 5 - to $10-$ years duration of diabetes mellitus. The main predisposing factors were peripheral neuropathy and peripheral vascular disease ${ }^{14}$. Other contributory risk factors include obesity, sedentary life style, poor glycemic control, and alcoholism. Smoking has got special attention with 3 times higher incidence in this study supported by others which may mimic the disease process $^{14,15}$. DFU coexist with comorbidities like CKD that was shown in our study. Other systemic complications such as septic shock, diabetic ketoacidosis, hyperglycemic hyperosmolar state and hyponatremia which could be life threatening if not recognized and treated promptly. Among the 210 patient, most of the patients presented within Wagner G-I to G-3. Debridement and split thickness skin graft were the most frequently performed surgical intervention for DFU in present and the same in other studies ${ }^{14,15}$. Maximum patients of G-1,2 thus saved conservatively or by minimal intervention where in G-3, 4 and 5 patients need to be amputated. The disease was a financial burden to the patient as the average hospital stay was 15 days.

\section{Conclusion:}

Early presentation of diabetic foot ulcer patients can be prevented from minor or major amputation. We should emphasis to identify the high risk foot and should arrange health education programs so that the diabetic patients can know about the importance of optimizing blood glucose level, using appropriate footwear, avoiding foot trauma, performing self foot examination daily by using mirror and reporting any changes to health care profession to prevent diabetic foot ulcer. So the outcome of management is better in G-1 and G-2 than G-3, G-4 and G-5.

\section{Reference:-}

1. International Diabetes Federation Diabetes atlas available at: http://www.eaqtlas.idf.org/prevalence/ All diabetes. Accessed 17 may 2006.

2. Abegunde Do, mathers $C D$, Adom $T$, ortegon $M$, strong $\mathrm{K}$. The burden and costs of chronic disease in low-income and middle income countries. Lancet 2007; 370(9603). 1929-1938 doi : 10.1.16/sol406736(07) 61696-1 (pub-med) (Cross Ref)

3. H jelm K, mufunda E, nambozi G, Kemp J, preparing nurses to face the pandemic of diabetes mellitus: a literature review : JADV nurs. 2003; 41(5): 424424. doi : 10.1046/J. 1365-2648.2003.02548x [Pub med]

4. wild S, Roglic G, Green A, Sicree R, King H, Global prevalence of diabetes estimates for the year 2000 and projections for 2030. doi : 10.233 7/diacare 27.5.1047 [pub-med] [cross Ref] Risle csses ment

5. Alcbaric, logerfo vascular diseare of the lower extrimities in diabetes mellitus : Etiology and management, 'Joslin's Diabetes mellitus'. 14th edition. USA : Lippncott Williams and coilleins 2005.PP 1124-1131

6. Forozandeh F. Azozahari A, Abolhasani F, Larijani B. Neurologic and vascular assesment of foot in diabetic patients referred to diabetes clinic in Dr. Shariati hospital in 2003-4. iranian J Diabetes Lipid. 2005; (4):43-51.

7. Poloers A. Neuropathy and diabetes Mellitus Harrisons principle of internal medicine 17th editions USA: MC Graw-Hill; 2008. 2292PP. 
8. Shahrad Bejestani H, Motabar AR. Assesment of diabetic foot ulcers predisposing factors and its outcomes in patients with diabetic foot syndrome hospitalized in Itazrat Rerel-e-Aleram hospital in Tehram during 1996-2001. Jiran Med Sci unc 2004; 39: $77-84$.

9. Boulton AArmstrong Albert S Fryleberg Hell man R, leirle man $\mathrm{M}$, Comprehensive foot examination and risu assesment Diabetes care 2008; 31 (8) : 16791685 [PMC treearticle] [Pul Med] 3,7

10. Lowp pathogenesis of Diabetic Neuropathy Joslines Diabetes mellitus. 14th editions USA: Lippin cott williams; 2005 PP 839-851

11. Giurini $\mathrm{J}$ the diabetic foot strategies for treatment and prevention of ulceration; Joslins diabetes Mellitus 14th edition USA: Lippincott williams and wiluens; 2005 PP 1112-1121
12. Morbach s, Lutale JK, viswanathan V, Mollenberg J, Ochs HR, Rajashekar S, et al. Regional differences in risk factors and clinical presentation of diabetic foot lesions. Diabet Med. 2004; 21:91-5. [PubMed: 14706061].

13. Armstrong DG, Wrobel J, Robbins JM. Guest Editorial: Are diabetes-related Wounds and amputations worse than cancer? Int Wound J. 2007; 4:286-7. [PubMed: 18154621]

14. Muduli IC, Ansar PP, Panda C, Behera NC. Diabetic Foot Ulcer Complications and Its Management-a Medical College-Based Descriptive Study in Odisha, an Eastern State of India. Indian Journal of Surgery. 2015 Dec 1; 77(2):270-4.

15. Bansal E, Garg A, Bhatia S, Attri AK, Chander J. Spectrum of microbial flora in diabetic foot ulcers. Indian J Pathol Microbiol. 2008; 51:204208. doi: 10.4103/0377-4929.41685 